\title{
Die konsep van eer as sleutel tot die interpretasie van Psalm 133
}

P J Botha

(UP)

\section{ABSTRACT}

The concept of honour as a key to the interpretation of Psalm 133

Despite the fact that its text is quite straightforward, the imagery of Psalm 133, combined with its brevity, poses some interpretational problems. In this paper it is proposed that consideration of the role played by the societal core value of honour in Israel can throw some light on the questions about the relationship between and the combined meaning of images such as that of brothers living together, oil running down from the beard of Aaron, and Yahweh's commanding of blessing from Zion.

\section{DIE PROBLEMATIEK VAN PSALM 133}

'n Voorlopige uiteensetting van die teks en 'n vertaling van Psalm 133 sou soos volg daar kon uitsien:

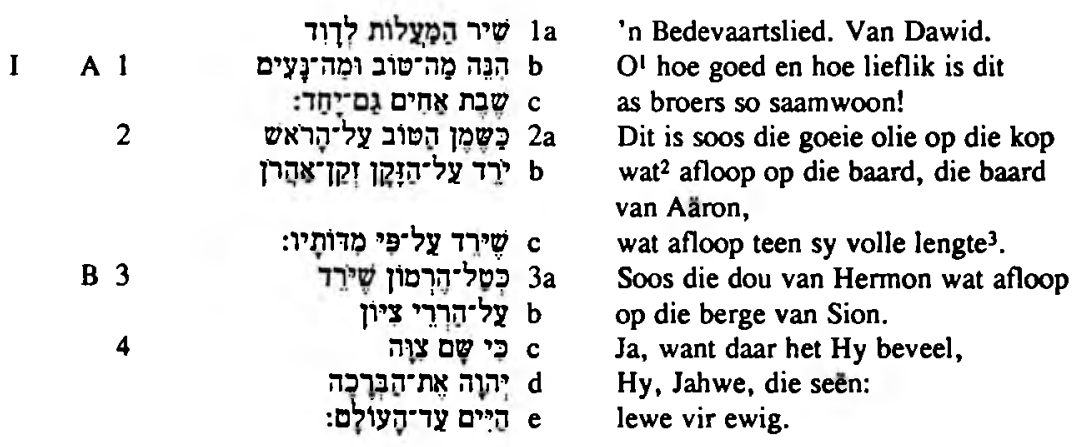

Die pragtige beelde van hierdie psalm is goed bekend en geliefd onder gelowiges. Tog loop ' $n$ mens die gevaar om dit as mooi te beskryf sonder om werklik te verstaan wat die psalm wou kommunikeer, en daarom ook wat dit aan die moderne leser moet kommunikeer. Dit word dan hanteer soos 'n preek wat strelend op die oor is, maar eintlik leeg na die prediker terugkeer. Wie is die broers wat volgens vers 1 so pragtig saamwoon? Wat het hulle vredige toestand met Aäron se baard en lengte (of: klere, volgens 
sommige) te doen? Hoe loop die dou van Hermon, ver buite Israel, op Juda se Sionsberge af? En hoe beveel Jahwe lewe vir ewig?

Op hierdie vrae is talle antwoorde gegee, baie daarvan logiese en aanvaarbare antwoorde. Hierdie artikel kan nie regtig op daardie pogings verbeter nie, maar die invalshoek kan dalk tog 'n beter verstaan bring omdat dit 'n verband lê tussen die (skynbaar) uiteenlopende gedagtes. Dié invalshoek is naamlik dat ' $n$ poëtiese analise van die gedig gekombineer word met 'n sosiaal-kritiese benadering. Uit die kombinasie van dié twee analises, hoop die skrywer, sal daar nuwe lig val op die probleme waarmee die verklaarder te kampe het. In die besonder speel die begrip eer, wat as kernwaarde van die Israelitiese samelewing gegeld het, in hierdie psalm so 'n belangrike rol dat beklemtoning van aspekte wat daarmee te doen het, 'n nuwe verstaan kan bring.

\section{DIE PSALM AS POËTIESE KUNSWERK}

Volgens die indeling hierbo bestaan die gedig uit twee strofes wat elkeen twee versreëls het. Die metrum is dan $4+3,3+3+3,2+2$ en $3+2+2$. Dit is dus telkens die slotreël wat drie versbene bevat. Die twee strofes is ook inhoudelik parallel, aangesien elk 'n vergelyking bevat: In strofe $A$ word die saamwoon van broers vergelyk met goeie olie wat afloop van die kop van Aäron af teen sy baard en teen sy volle lengte langs (of teen sy klere langs - die probleem is reeds aangeroer en word later weer bespreek); in strofe B word dieselfde saak vergelyk met die dou van Hermon (ook 'n "kop" 4 in sekere sin) wat afloop op die berge van Sion. Dat daar in die meervoud van "berge" sprake is, is dus nie 'n fout of ' $n$ toevalligheid nie, maar is moontlik juis so gekies om met die meervoud van "mates" te korrespondeer.

Die logiese onmoontlikheid dat die dou van Hermon op die berge van Sion kan afloop, hoef nie die ondersoeker te dwing om die teks te emendeer soos onder andere Gunkel ${ }^{5}$ gedoen het nie. Die Jordaanrivier ontspring in die voetheuwels van die Hermongebergte. Hoewel die Jordaan nie naby Jerusalem verbyvloei nie, deel die hele Israel eintlik in die seën wat ontspring uit die oorvloedige nagtelike dou wat op Hermon presipiteer. Die populêre opvatting was moontlik ook dat die Hermonberge die dou voorsien het wat gedurende die somermaande in die hele Palestina voorgekom het ${ }^{6}$.

Hierdie dubbele vergelyking het ook tot gevolg dat daar herhaling van 'n aantal terme in die twee strofes is: Die reeks 


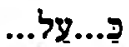

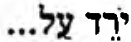

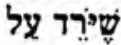

van strofe A word in strofe B herhaal as

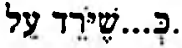

Die twee voorkomste van vergelykings waarin dieselfde onderwerp verduidelik word, toon literêr aan dat die saamwoon van die broers waarvan in vers lc sprake is, een van die betekenisfoci van die gedig is. Dit word verder bevestig deur die sinonieme parallelisme en herhaling van die vraagwoord in vers $1 \mathrm{~b}$, sowel as die gebruik van hulpmiddel is) en die voorkoms van (wat dieselfde beklemtonende funksie het).

Die belang van die eerste versreël vir die verstaan van die gedig word selfs verder onderstreep deur herhaling van (vers $1 b$ ) in vers $2 a$ en die alliterasie en assonansie van שֶׁ 1c en vers 2a voorkom. Daarmee word gesê: Die saamwoon van broers is so goed soos vreugdeolie of soos die salwingsolie op die kop van Aäron? Die relatiewe partikel $\forall$ in vers $2 c$ en $3 a$ sit hierdie assosiasie verder voort: Die saamwoon van broers is so goed soos die salwingsolie van Aäron wat afloop teen sy klere, soos die dou van Hermon wat afloop op die berge van Sion. Daar is natuurlik 'n sterk ooreenkoms tussen die twee vergelykings (olie en dou vorm as ' $t$ ware 'n parallelle woordpaar; Hermon as hoë berg korrespondeer met die kop van 'n persoon). Maar dit is nie nodig om die tweede vergelyking op te neem as 'n verduideliking van die eerste een soos wat Adele Berlin ${ }^{8}$ doen nie.

Die spreuk oor die saamwoon van broers in vrede aan die begin van die gedig word gebalanseer deur 'n stelling aan die einde oor die seën wat Jahwe beveel het. Hierdie twee uitsprake omarm die twee vergelykings in

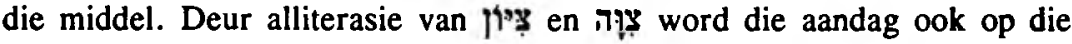
einde van die gedig gefokus. Dit is ook moontlik om die ' van die vierde versreël as 'n recitativum' te lees: "Ja seker, dár het Jahwe die seën beveel...". In daardie betekenis sou dit dan presies korrespondeer met die הִ הִarmee die eerste versreël begin. Sodoende word die korrespondensie tussen die begin en die slot van die gedig uitgelig, en kom beide stellings se verband met die vergelykings in die korpus van die gedig beter na vore.

Dit blyk dus dat die gedig opgebou is rondom twee elliptiese brandpunte: 'n stelling aan die begin en nog een aan die einde. Beide stellings 
word emfaties versterk en beide hou verband met die vergelykings in die sentrale deel. Nadat dit vasgestel is, kan die bespreking nou fokus op die betekenis van hierdie twee brandpunte.

\section{DIE SOSIALE ASPEKTE VAN PSALM 133}

Wat word bedoel met die "saamwoon" van "broers" in Psalm 133? Crow10 gee ' $n$ nuttige oorsig oor die verklarings wat al aangebied is. Sommige sien in die woordeskat en konstruksie van vers $1 \mathrm{~b}$ en $\mathrm{c}$ 'n wysheidsagtergrond. Die wysheidsuitspraak oor broederlike harmonie (vermoedelik in gesinsverband) sou dan later 'n kultiese kleur gekry het deurdat redaktors uitbreidings gemaak het wat na die priester van alle priesters, Aäron, verwys. Die gevolglike boodskap van die psalm in sy redaksionele baadjie is dan dat harmonie tussen broers beloon sal word met die gawe van die ewige lewe.

'n Tweede moontlikheid is om die verwysing na broers uit die staanspoor kulties op te neem. Daarvolgens sou dit dui op die geloofsgemeenskap van Israelitiese mans. Die seën sou dan spesifiek voortspruit uit die saamwees as gelowiges in Sion, die plek van aanbidding wat deur Jahwe uitgekies is. Keel" wys byvoorbeeld daarop dat die term nomium 'n sterk godsdienstige kleur gekry het wat dit ook na-eksilies (en dus in hierdie psalm) behou het.

'n Derde moontlikheid is die weg wat deur Adele Berlin ingeslaan is. Volgens haar moet die betekenis van broers hier primêr nasionalisties ${ }^{12}$ opgeneem word. Dit is dan ' $n$ verwysing na die hereniging van die twee ryke van Israel en Juda'13. Crow wys daarop dat die verbinding van die terme ישבושבת ' met 'n paar plekke in die Ou Testament voorkom, nie altyd met presies dieselfde betekenis nie. In Genesis 13:6 en 36:7 dui dit byvoorbeeld op die saambestaan van 'n uitgebreide familie wat deur hulle bande met die patriarg aan mekaar verbind is. In daardie geval het dit daaroor gegaan dat die land nie vrugbaar genoeg was om hulle almal te onderhou nie.

In Deuteronomium 25:5 verwys dieselfde uitdrukking na die Leviraatshuwelik wat in werking moet tree waar "broers saamwoon", vermoedelik dus waar die oorlewende broer nog beskikbaar is om sy plig teenoor sy skoonsuster te vervul. Die reg van die weduwee om by die familie te bly woon, word dus op hierdie manier beskerm.

In Rigters 19:6 weer verwys hierdie woorde na gesamentlike deelname aan 'n maaltyd, dus nie "saamwoon" nie, maar letterlik "saamsit". Kissane is ' $n$ voorbeeld van iemand wat die moontlikheid oorweeg dat dit 
hier gaan oor die saamwees van 'n gemeenskap van pelgrims wat deelneem aan 'n offermaaltyd 14 .

Laastens wys Crow ook op die voorkoms van die terme in Jeremia 31:24, wat volgens hom na 'n soortgelyke situasie verwys as dié in Psalm 133, naamlik die na-eksiliese hervestiging van die mense van Juda in hulle eie land en hulle gesamentlike aanbidding in Jerusalem ${ }^{15}$. Hyself sou daarom verkies dat daar nie 'n skerp onderskeid gemaak word tussen 'n "nasionalistiese" en 'n "kultiese" interpretasie nie. Volgens hom is beide interpretasies maar net aspekte van dieselfde realiteit ${ }^{16}$.

Crow het waarskynlik baie naby aan die korrekte interpretasie gekom, juis omdat hy (onwetend of intuitief) die regte koers ingeslaan het. Dit is inderdaad so dat ervarings op interpersoonlike, sosiale vlak baie dikwels ook op nasionale en religieuse vlak gereflekteer word. Een model wat hierdie waarheid onderstreep, is die model waarvolgens eer en skande as kernwaardes in die kultuur van alle volke wat in antieke tye rondom die Middellandse See gewoon het, beskou word ${ }^{17}$. Onder hierdie volke word Israel ook ingesluit. Eer was die erkenning van 'n persoon se aanspraak op sosiale waarde en was een van die belangrikste aspekte wat die Israeliete se lewens- en wêreldbeskouing gereguleer het. Die strewe om erkenning te kry vir die aanspraak op ' $n$ bepaalde eer was een van die belangrikste dryfvere in menslike optrede ${ }^{18}$.

Die beskouings oor persoonlike eer het ook gegeld op nasionale vlak, asook ten opsigte van godsdiens ${ }^{19}$. Wanneer God Israel seënn ${ }^{20}$, is dit geinterpreteer as Goddelike sanksie van hulle aanspraak op eer as 'n nasie. Die afwesigheid van God se seën, daarenteen, is gesien as 'n ontkenning van hulle aanspraak op eer as nasie ${ }^{21}$. Sonde is gewoonlik deur die profete uitgewys as die oorsaak van God se onttrekking en hulle beskaming onder die familie van nasies deurdat een of ander nasionale krisis hulle getref het $^{22}$. Sodanige beskaming het daartoe gelei dat ander volke hulle gespot het, aangesien hulle aanspraak op 'n besondere verhouding met dié God wat aan hulle aansien moes verleen, nie gerealiseer het nie.

Nou is dit so dat Psalm 133 op verskeie vlakke bedekte verwysings bevat na die kernwaarde van eer en die wyse waarop die volk dit kon verkry. Om by die mees opvallende te begin, salwing het gewoonlik gepaard gegaan met en is gesien as die toekenning van 'n bepaalde eer ${ }^{23}$. Dit het nie alleen vir die ampte van priester, profeet en koning gegeld nie, maar was ook in ' $n$ meer sekulêre sin die teken van toegekende eer. Dit kan afgelei word daaruit dat dit juis die kop was wat gesalf is. Die kop was 'n besondere sensitiewe deel van enige persoon met betrekking tot die prosesse van toekenning van eer of die wegneem daarvan, naamlik beskaming. 
Die persoon wat op sy kop gesoen, gekroon of gesalf is, het eer bygekry. Die persoon wat in die gesig gespoeg of geslaan is of op wie se nek of kop getrap is, is verneder en het eer verloor. Die verwysing na Aăron se salwing herinner dus aan die verhouding tussen God en sy volk. Deur aan Aäron hierdie ereposisie te gee, het God aan sy volk 'n eer bewys. Hy het hulle in ' $n$ besondere verhouding tot Homself gestel deur aan hulle 'n opeenvolging van hoëpriesters gegee. Aäron en sy eer simboliseer in hierdie gedig dus die hoëpriesterskap, maar terselfdertyd ook die eer van die volk, 'n eer wat "afloop" oor geslagte van hoëpriesters en gevolglik ook geslagte van aanbidders van Jahwe. Moontlik is dit in hierdie sin dat aan die einde van die gedig gesê word dat Jahwe "lewe vir ewig" as seën "be-

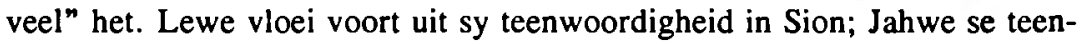
woordigheid is volgens die Sionsteologie 'n permanente toesegging aan Jerusalem ${ }^{24}$.

Die vermelding van die baard is eweneens 'n verwysing na eer. Slegs iemand met ' $n$ bepaalde geslagsrol en posisie van eer kon aanspraak maak daarop dat hy ' $n$ volle baard het. Die gedwonge afskeer van 'n baard was ' $n$ uiterste belediging met gepaardgaande vernedering van die eienaar daarvan ${ }^{25}$. Die vrywillige afskeer van die baard as teken van rou, of die latere bedekking daarvan met dieselfde doel of andersins as teken van verleentheid, dui ook op hierdie simboliese erewaarde van die baard26. Dit is daarom nie van uiterste belang om te bepaal of die gedig van die ampskleed van Aäron praat of van sy liggaamslengte nie ${ }^{27}$. Moontlik verwys "sy lengte" hier selfs na die lengte van die baard. In al drie gevalle sou dit egter ' $n$ bedekte verwysing wees na die eer wat aan die posisie van priester, veral die hoëpriester, gekoppel was. Dit was inderdaad dié ereposisie in Israel, omdat die persoon se eer deur God self toegeken is. 'n Lang baard simboliseer groeiende eer oor 'n lang periode. Indien die lengte van die baard wel ter sprake kom, sou dit moontlik ook opgeneem kon word as 'n verwysing na die opvolging van hoëpriesters, dus na Jahwe se duratiewe seën en toekenning van eer aan sy volk. Soos reeds hierbo genoem, sou so 'n interpretasie die verklaring van "lewe vir ewig" as verwysende na Jahwe se belofte van voortgesette seën en teenwoordigheid in Sion, goed ondersteun.

Die eerste strofe van die gedig sê dus dat die harmonieuse saamwoon van mense uit God se volk (as broers in die verband van die uitgebreide familie of moontlik as burgers op nasionale vlak) aan die volk eer verleen, want daardie saamwoon is gelyk aan die eer wat Jahwe aan die hoëpriester toeken. Dit is 'n eer wat nie afneem nie, maar wat toeneem tot dit die hele wese omsluit; tot dit as ' $t$ ware die persoon van kop tot tone omsluit ${ }^{28}$. 
In strofe $B$ word voortgegaan met die beeld oor die toekenning van eer. Die dimensie van die vergelyking verander egter van 'n kultiese ereposisie na 'n nasionale ereposisie. Die vermelding van plekname soos Hermon en Sion is ' $n$ aanduiding daarvan dat dit hier oor die grondgebied van Israel gaan. Die vergelyking (of dan ten minste: die verband) tussen Hermon en Sion toon aan dat dit handel oor 'n nasionale aanspraak op eer. En nasionale eer word toegeken of gesanksioneer deurdat Jahwe oor Israel sy seëninge van versorging uitstort. In die slot van die gedig word daardie seën selfs by die naam vermeld: Dit is die seën wat Jahwe in Sion ${ }^{29}$, sy eie posisie van eer, afgekondig het. Die woord "beveel" beteken in hierdie slotreël van die gedig soveel as 'n Goddelike dekreet. Die inhoud van daardie seën is Jahwe se versorging van sy volk, sy voorsiening van lewensmiddele aan hulle waardeur hulle in die oë van die nasies geëer word. Sy bevel oor seên is die bewys van sy eie teenwoordigheid by sy volk in Sion en is dus die bevestiging van hulle nasionale eer ${ }^{30}$.

Op hierdie wyse word dus gesê: Wanneer lede van God se volk ${ }^{31}$ in vrede en harmonie saamwoon, dan is dit 'n bevestiging van die seën van Jahwe wat na vore kom in ' $n$ besondere kultiese verhouding tussen Hom en sy volk. Sosiale verhoudings staan nie los van die godsdiens nie. Omgekeerd kan gesê word dat Jahwe die hoëpriester bedeel het met besondere eer; en daardeur word ook aan die volk eer verleen ${ }^{32}$. Maar dit is ook 'n bevestiging van die seën van Jahwe op die landbou, omdat Hy nie alleen die oorsprong van hulle welstand is nie, maar (daarmee saam) ook van hulle posisie van eer onder die nasies. God se seën op die landbou staan dus ook nie los van die godsdiens nie ${ }^{33}$.

Skematies kan dit soos volg voorgestel word:

Harmonie op sosiale vlak is soos

die seën op kultiese vlak

wat blyke gee van die volk se posisie van eer;

eer wat ook na vore kom in Jahwe se versorging van sy volk

en wat sy oorsprong in Jahwe se teenwoordigheid in Sion het.

Dit is dus nie nodig om te vra na wie die "broers" in Psalm 133:1 verwys nie; dit sluit alle sosiale interaksie in: dié tussen bloedbroers, tussen volksgenote en tussen geloofsgenote. Die eer van die hoëpriester bestaan nie alleen in dit wat Jahwe kragtens sy ordening aan hom toeken nie, dit bestaan ook in die orde en harmonie wat daar in die kultus heers. Die seën wat Jahwe (oor sy volk) in Sion "beveel", word gereflekteer in sy gawes in die natuur, maar dit kom ook na vore in die harmonie onder sy volgelinge. 
God gee lewe, lewe deur sy seën in sosiale verhoudinge, lewe deur sy seën in die kultus, lewe deur sy seën in die landbou. Hierdie seën en die eer wat dit bring, dit is lewe vir altyd! Dit is opmerklik dat die boek Maleagi tot 'n baie groot mate dieselfde sake met mekaar in verband stel, hoewel dit dár

juis handel oor die gebrek aan eer wat Israel ervaar vanweë die gebrek aan eer vir God en harmonie op sosiale vlak en die gevolglike afwesigheid van Jahwe in die kultus $^{34}$.

\section{KONKLUSIE}

Die inleidende stelling van hierdie psalm is nie soseer ' $n$ wysheidsuitspraak of 'n spreekwoord nie. Dit is bedoel as 'n oproep tot vrede en harmonie onder almal wat hulleself beskou as deel van die huis van God, en dus as broers. Sodanige harmonie is 'n illustrasie van die goeie gesindheid van Jahwe, van die eer wat Hy aan sy volk skenk onder die familie van nasies. Daardie eer manifesteer ook in die seën wat op die hoëpriester as simbool van die kultus heers; ' $n$ seën wat oorvloediglik alles oordek soos salwingsolie wat afloop oor die baard en liggaam van die priester. Daardie eer manifesteer ook in die seën wat op die landbou rus, 'n seën wat Jahwe vanuit die kultus beveel en wat lewe (en eer) gee in lengte van dae. Vanuit hierdie perspektief beskou, vorm die beelde van Psalm 133 'n eenheid en is dit nie langer nodig om na die kultteologiese verwerking van 'n (meer profane) "Grundtext" te soek nie ${ }^{35}$.

\section{NOTAS:}

1 Die uitroep funksioneer hier waarskynlik bloot as emfatiese versterking. Vergelyk L D Crow, The Songs of ascents (Psalms 120-134), their place in Isruelite hisfory and religion, SBL Dissertation Series 148, Scholars Press 1996, 107 nota a.

2 Die eerste voorkoms van 7 ' word soms deur kommentatore van 'n relatiewe partikel voorsien om dit in lyn te bring met die ander twee voorkomste van dieselfde vorm. Bardtke het die voorstel in die kritiese apparaat van BHS gemaak en het onder andere navolging gevind in Crow, $a w, 107$. Dit is egter geensins 'n vreemde konstruksie om 'n relatiewe sin met 'n partisipium in te lei nie. Om al drie voorkomste van $77 ̄$ ' dieselfde te wil he, getuig van vormdwang en 'n gebrek aan respek vir die digter se kreatiwiteit.

3 Die uitdrukking מדith, soms opgeneem as 'n meervoudsvorm van in die betekenis van "erekleed", skep probleme. Die vroulike meervoud sou die enigste voorkoms daarvan in die Hebreeuse Bybel wees. Dit moet moontlik eerder teruggevoer word na הᄁְ̣, "mate". Othmar Keel, “Kultische Brüderlichkeit - Ps 133", Freiburger Zeitschrift vol 23 (1976), 68-80 het 'n sterk argument daarvoor uitgemaak dat die frase nie na klere verwys nie, maar juis na 
Aäron se volle lengte. Bardtke (in die apparaat van BHS) wonder egter sonder meer of die hele reël nie moontlik geskrap moet word nie. Vir hom, soos vir $\mathbf{H}$ Schmidt, Die Psalmen, J C B Mohr 1934, 236, H-J Kraus, Psalms 60-150, translated by H C Oswald, Augsburg 1989, 484 en nog vele ander lyk die verwysing na Aäron baie verdag. Vergelyk egter die bespreking hieronder. Hermonberg het 'n hoogte van $\mathbf{2 8 4 0}$ meter, teenoor die Sionsberge se kruin van slegs 828 meter. Die gegewens is uit $\mathrm{Y}$ Aharoni \& $\mathrm{M}$ Avi-Yonah, The Macmillan Bible Atlas 1974, 15.

5 H Gunkel, Die Psalmen, übersezt und erklärt, Vandenhoeck \& Ruprecht 1926, 571-572.

D Baly, The geography of the Bible, a study in historical geography, Harper \& Row 1957, 194.

7 Die uitdrukking הפטָ verwys volgens sommige spesifiek na die olie waarmee die hoëpriester, in die besonder Aäron, gesalf is. Vergelyk Crow, $a w$, 112. Dennis Sylva, Psalins and the transformation of stress. Poetic-communal interpretation and the family, Peeters Press (Louvain Theological \& Pastoral Monographs 16) 1993, 232 redeneer oortuigend dat hier opsetlik dubbelsinnig te werk gegaan word deur die outeur van die psalm deur na beide soorte olie te verwys.

8 Adele Berlin, "On the interpretation of Psalm 133", in Directions in Biblical Hebrew Poetry, red E R Follis (JSOT Suppl 40), Sheffield Academic Press 1987, 141-147, 144.

9 Dit is ook hoe Crow ( $a w, 108$ nota $f$ ) dit opneem. Hy roep Waltke \& O'Connor tot getuies. Vergelyk B K Waltke \& M P O'Connor, An introduction to biblical Hebrew syntex, Eisenbrauns 1990, par 39.3.1d, 657.

10 O'Connor, a w, 109-112.

11 O Keel, $a w, 77$.

12 Adele Berlin, $a w, 142-143$. Berlin wys die moontlikheid dat dit oor gesinslewe handel af omdat sy reken die verhouding tussen mans en vrouens en mans en kinders kan in die Psalms vermeld word (vgl Pss 127 en 128), maar nie die verhouding tussen broers nie: "praise of family life, in itself not a common theme in Psalms, is more likely to speak of wife and children ... than of brothers". Dit lyk egter juis waarskynlik dat hier, soos in daardie twee bedevaartsliedere, na familiebande verwys sal word.

13 "The psalm expresses a hope for the reunification of the north and south with Jerusalem as the capital of a united kingdom", vergelyk Berlin, $a w, 142$.

14 Vergelyk E J Kissane, The Book of Psalms, translated from a critically revised Hebrew text, Vol II (Psalms 73-150), Browne and Nolan 1954, 274.

15 Crow, $a w, 111$.

16 Crow, $a w, 112$.

17 Vergelyk J Plevnik, "Honor/shame" in: J J Pilch \& B J Malina (reds), Biblical social values and their meaning, a handbook, Hendrickson 1993, 95-104, 95.

18 Vergelyk B J Malina, The New Testament world - insights from cultural anthropology, John Knox Press 1993, 28.

19 J Pilch, aw, 97.

20 Byvoorbeeld met reën of dou, vergelyk Deuteronomium 32:2; Job 29:23; Psalm 72:6; en Maleagi 3:10 as voorbeelde waar sodanige presipetasie as simbole van seēn geld. 
$21 \quad$ Idem.

22 Idem.

23 B J Malina, $a w, 35$.

24 Vergelyk byvoorbeeld 2 Samuel 7:13 en Psalm 48:9.

25 Vergelyk 2 Samuel 10:4-6. Vergelyk ook O Keel, $a w, 70$ nota 8.

26 Vergelyk byvoorbeeld Jesaja 15:2, Jeremia 41:5, Miga 3:7.

27 O Keel, $a w, 71-75$ het aangetoon dat dit waarskynlik is dat die skrywer na die lengte van Aäron verwys het en nie na die kraag van sy klere nie. Die uitdrukking 2 צ' vertaal word met "ooreenkomstig", dus oor sy volle lengte.

28 Die twee terme "kop" en "lengte" tree hier dus op as merisme wat ten doel het om die hele wese van die hoëpriester in te sluit.

29 Rendsburg (G A Rendsburg, Linguistic evidence for the northern origin of selected psalms, Scholars Press (SBL Monograph Series 43) 1990, 91-93) se betoog dat daar oorvloedige linguïstiese bewyse is dat hierdie psalm in die Noordryk geskryf is, oortuig nie heeltemal nie in die lig van die sentrale klem wat Jerusalem hier kry.

30 Die omgekeerde van hierdie toestand van eer, naamlik uiterste vernedering deurdat die seën terugetrek word, word treffend in verskeie eksiliese en naeksiliese tekste geillustreer. Vergelyk byvoorbeeld Klaagliedere 2.

31 Net soos die verwysing na "broers" nie suiwer op die manlike geslag betrek kan word nie, kan die betekenis ook nie tot bloedfamilie beperk word nie. Die bedoeling moet wyer wees: 'n kultiese of nasionale gemeenskap.

32 Volgens Eksodus 30:29 word alles wat die hoëpriester aanraak as hy met hierdie olie gesalf is, ook heilig.

33 Vergelyk byvoorbeeld Haggai 1:4-11.

34 Vergelyk byvoorbeeld Maleagi 2:9-11, 3:10-12.

35 Soos byvoorbeeld gedoen word deur Seybold nie. Vergelyk K Seybold, Die Wallfahrtspsalmen, Studien zur Entstehungsgeschichte von Psalm 120-134, Neukirchener Verlag (Biblisch-Theologischen Studien 3) 1978, 25-27. 